\title{
Editorial: Strengths, Risks and Limits of Doing Participatory Research in Migration Studies
}

\author{
Diana Mata-Codesal ${ }^{1}$, Laure Kloetzer ${ }^{2}$ and Concha Maiztegi ${ }^{3}$
}

\begin{abstract}
This special issue, entitled "Participatory methods in migration research", deals with the methodological challenges and ethical implications of applying participatory methods with migrant populations. Participatory research is often used as a general term for a variety of research projects using different methods, including action research, collaborative research, community-based research, co-creation or some arts-based projects. This special issue assumes that participatory research involves a different epistemology that allows for new insights, reflections and stories. Consequently, one of its main characteristics is the horizontal relationship between researchers and participants, based on the recognition of all the people involved as equal human beings collaborating on a particular research question. Through the SI, one of the themes that is discussed, from a variety of perspectives in the field of migration studies, is power distribution. The challenge is to achieve a more equal share of power among all those involved in the research process. From the set of articles presented here, another theme that emerges strongly is the struggle for social justice beyond the research process itself. The special issue contains a range of participatory research approaches in the field of migration studies from different parts of the word (Africa, Europe, USA) revealing a growing interest in these methodologies.
\end{abstract}

Keywords: participatory methods; migration studies; participation; power; gender.

\section{Participatory Research in Migration Studies}

50 years on, Sherry R. Arnstein's critical words on participation in policy and social planning remain very relevant: "The idea of citizen participation is a little like eating spinach: no one is against it in principle because it is good for you. Participation of the governed in their government is, in theory, the cornerstone of democracy-a revered idea that is vigorously applauded by virtually everyone. The applause is reduced to polite handclaps, however, when this principle is advocated by the have-not blacks, Mexican Americans, Puerto Ricans, Indians, Eskimos, and whites. And when the have-nots define participation as redistribution of power, the American consensus on the fundamental principle explodes into many shades of outright racial, ethnic, ideological, and political opposition" (Arnstein, 1969, p.216). According to her, what participation should be, however, is very different: "citizen participation is a categorical term for citizen power. It is the redistribution of power that enables the have-not citizens, presently excluded from the political and economic processes, to be deliberately included in the future. It is the strategy by which the have-nots join in determining how information is shared, goals and policies are set, tax resources are allocated,

\footnotetext{
${ }^{1}$ Diana Mata-Codesal, GER-Research Group on Reciprocity-Anthropology Department, the University of Barcelona, Spain. Email: d.mata.codesal@gmail.com.

${ }^{2}$ Laure Kloetzer, Institute of Psychology and Education, University of Neuchâtel, Switzerland. E-mail: laure.kloetzer@unine.ch.

${ }^{3}$ Concepción Maiztegui-Oñate, Pedagogía Social y Diversidad. Facultad de Psicología y Educación, University of Deusto, Bilbao, Spain. E-mail: cmaizte@deusto.es.
} 


\section{Strengths, Risks and Limits of Doing Participatory Research in Migration Studies}

programs are operated, and benefits like contracts and patronage are parcelled out. In short, it is the means by which they can induce significant social reform which enables them to share in the benefits of the affluent society" (ibidem, p. 216). Whereas her critical call was related to participation of citizens in State and local policies, it is fully relevant to the current analysis of the (non) participation of (non) citizens in supranational, national or local policies governing international migrations.

This special issue presents a range of participatory research approaches in the field of migration studies. More precisely, we could argue that most authors of this Special Issue would not spontaneously self-identify with the field of migration studies, although they have all been working, some of them for decades, on topics which are directly and undoubtedly relevant to it. They might instead self-identify as coming from the field of feminism, action-research or being "activistscholars" (as Valerie Francisco-Menchavez and Ethel Tungohan and Elsa Oliveira and Jo Varey explicitly do in their articles). The focus on the methodology of participatory research, which is not only a set of creative methods, as we will see below, but also an epistemology and an ethics of research, implies a different way of relating to our research objects, participants, and colleagues, superseding academic divisions among specialisation and expertise. Following the steep increase in the number of papers linked to Migration Studies in the last 20 years, there has been a paralleled increase in the number of papers published drawing on qualitative methodology (Sirkeci et al., 2019). Although the study of migration was initially dominated by empiricist-positivist and quantitative approaches, by now there is an established and growing tradition of qualitative studies. However, in leading journals of the field, participatory research, action research, and the use of creative participatory methodologies remain uncommon. Most of the time, creative methodologies like photo-elicitation are used as support to traditional ways of conducting research without further social engagement with the communities or participatory ethos (see for example Long et al., 2014).

An interesting paradox is that other fields, not principally labelled as Migration Studies, have been developing a very strong qualitative and participatory tradition dealing with migrant populations. For example, researchers within the field of feminist studies, research aiming at decolonizing psychology and anthropology, culturally-sensitive research, social work, critical psychology or education, have frequently conducted innovative research with alternative, often culturally-relevant or arts-based methods, to engage mobile people in collective explorations of issues linked to migration (see for example Iosifides and Sporton, 2009; Kontopodis, 2012; O'Neill, 2008; Lenette, 2019). We could even argue that outside Migration Studies, there has been a surge of explorative, innovative creative participatory research involving migrant populations. However, these highly creative and socially responsible research trends seem disconnected from the strongly emerging and recently structured field of Migration Studies. This Special Issue aims at bridging this gap by making a set of participatory research papers highly visible in the field of Migration Studies. We believe that participatory research, with all its intrinsic methodological creativity but also research ethics, practice and interest for social action, has a lot to bring to the field of Migration Studies when it comes to both understanding and transforming the life experience of mobile populations.

Participatory research (PR from here onwards) questions well-established dichotomies such as those existing between researcher and research participants, or between academia, activism and social work (Pereira et al., 2016). So far, though, these studies have not received systematized attention and to a large extend remain as isolated small case studies. Trying to redress this situation, this special issue aims to showcase overall connections and developments by providing an updated 
account of participatory approaches in migration studies, and to provide a forum to reflect on the possibilities, limits and challenges of making use of participatory methods in migration research.

\section{Defining Participatory Research}

Participatory research is an umbrella term under which nests, more or less comfortable, a wideranging variety of research projects using different methodological approaches and research techniques, whose main aim is to achieve an equal distribution of power among all those involved in the research process. Reciprocity between community participants and researchers, sharing and valuing various forms of knowledge, are essential elements of PR. PR is not only a methodological approach, it is also an organizing strategy (Fox et al., 2010), an orientation to inquiry (Bradbury and Reason, 2006), a research tactic (see Valerie Francisco-Menchavez and Ethel Tungohan in this SI), an ethical stance, an epistemological questioning, and a human encounter (Marit Aure et al. in this SI). The ten articles in this special issue well exemplify this breadth of scope, each of them operationalizing PR in specific ways and by drawing on specific technical strategies related to PR.

PR projects are termed with a variety of names including action research, collaborative research, community-based research, co-creation, and even arts-based research. This terminology span reflects disciplinary differences and technique preferences but despite differences, PR "share a common set of core principles and characteristics" (Letiecq and Schmalzbauer, 2012, p.247). PR implies an understanding of the research process in which all parties involved (researchers, other research participants and even audiences) are conceived as co-creators in what is often an explorative process of knowledge production (Bradbury and Reason, 2006). Through participatory methodologies researchers contribute to create spaces for the co-creation of knowledge, in partnership with research subjects and institutions. Dialogic engagement is a key element for truly participatory projects to achieve less-hierarchical, non-extractive and more decolonized methodologies (Hennink et al., 2011, p.51). However, these spaces are not always conflict-free and the conditions for true dialogue are not always easy to achieve.

For the sake of clarity, we can arrange the diversity of terminologies and definitions of PR according to which steps of the research process are open to the participants for co-design and exploitation. This continuum would go from narrow conceptualizations of collaboratively problemdetection projects to critical emancipatory approaches which question the very basic foundations of what is considered as proper knowledge and who the experts producing such knowledge are. In this sense, PR is closely linked to decolonial and feminist understandings of doing research. A basic conceptualization of PR would conceive it as a problem-solving technique which often involves researchers and research participants working together to examine a problematic situation, action or issue (Milne, 2016). As it is, PR creates projects of social relevance for the communities involved. More complex and critical understandings of PR would emphasize the importance of the research process itself, as a dynamic educational process that enables and legitimizes social research and often leads to action. Thus, PR represents a way of overcoming prevailing extractivist logics of doing research. This latter approach is closely related to the work of Paulo Freire, with some of his developments concerning voice and participation being key for participatory research. In particular, the need to recognize the most vulnerable participants' voice, as well as their awareness processes, is a true challenge for researchers who need to develop what Martha Montero-Sieburth calls in her article in this special issue "cultural humility". These elements are all related to some of the postulates of Slow Academia and feminist approaches to academic life and purpose which go 


\section{Strengths, Risks and Limits of Doing Participatory Research in Migration Studies}

beyond finalist logics and focus more on the processes involved (Caretta and Riaño, 2016; Mountz et al., 2015).

Technique creativity is often an intrinsic feature of participatory research projects, which are frequently labelled after the selected research technique. Published research shows that PR pairs well with a broad range of research techniques, and in particular with arts-based ones such as video and other visual techniques, as well as embodied techniques like theatre and other performative methods. An important number of participatory projects has used photography, under for instance the form of photovoice (Wang and Burris, 1997; see also Magdalena Arias Cubas in this special issue), participatory photography or photowalks. Through this creative technique, PR projects offer a way of gaining new insights, reflections and narratives, through working with artistic methods and involving artists in the process. Non-academic participants themselves come to realize, reflect on, and express their experiences and views in a novel way that may not be captured in verbal and more conventional research methods. Similarly, reaching out and engaging with wider audiences through these newly acquired narratives is made possible, namely when artistic and creative practices are involved. Recognizing the potential of PR creatively to develop and engage with different research techniques does not have to mean falling into the negative consequences of what Derya Ozkul in her article in this special issue calls the "glorification of methods". The emphasis on "innovative and creative" methods (Wiles et al., 2011) can sometimes conceal the absence of meaningful participation and in some cases even disguise the one-sided nature in which so called participatory projects are implemented.

\section{What is Participatory Research good for?}

Compared to classical research strategies, participatory research is a more complex research process, as it involves simultaneous strategies for knowledge production and for social transformation. The ultimate objective of PR is social justice (Letiecq and Schmalzbauer, 2012) for which its core activities include not only research but also education and other actions (Balcazar, 2003).

Regarding knowledge production, participatory research improves research thanks to four main dimensions: 1) a sounder research question; 2) attention to complexity, social dynamics, power dynamics, and dynamics of change through long-term personal engagement with social situations and people; 3) social validation by research participants thanks to relationships of trust and the habitus forged by critical collaboration; and 4) explicit conceptualization of research as a learning process involving reflexivity, subjectivity, and emotions.

Firstly, participatory research requires a delicate interplay between the choice of a scientific question by the researchers, which is usually an epistemic runway object already grounded in a disciplinary literature and way of asking research questions, and openness to the redefinition of the goal of the research with the research participants, individually and collectively. True engagement of the research participants requires that the researchers do their best to pursue the research questions set by the research participants and local communities, usually linked to everyday life and challenges, as well as their own research questions, usually linked to a disciplinary tradition as well as personal life experience. Achieving a good balance between multiple interests regarding the goal of the research is essential and has consequences for the design of the research. The research question is stronger in participatory research because it has two related and complementary faces: a socially relevant face, and a scientific face. It is also evolving through the course of the research 
and the changing modes of participation involved. This epistemic flexibility is a strength of participatory research, which closely and dynamically follows the lessons learnt from the fieldwork, the concerns of the participants and the theoretical interests of the researchers. However, it can be a drawback to secure funding for the research, as all research questions cannot be defined in advance: only one thing is sure - they will evolve through the research process itself.

Secondly, building trust with research participants, who are also research partners, is a key dimension of participatory research. Among its main advantages, we can argue that the long-term engagement of researchers with local communities and specific people makes the researchers less naïve regarding the overgeneralisation of conclusions that could be drawn in comparison to shorter engagement with the field from a "single-point, static snapshot" of the situation. The complexity of social situations, the power dynamics at all levels, and the dynamics of change at the individual and collective levels better appear with long and informal conversations with research partners as well as with repeated research events and discussions. Working together (professional researchers and research participants, sometimes also with artists or activists) allows all to better understand their different points of view, life experiences, life concerns, life trajectories and past, present and future interests.

Thirdly, truly participatory research requires validation by research participants at all steps of the research process: definition of the research object and goal of the research, choice of methods, discussion of first empirical findings, construction and discussion of analyses, construction and discussion of conclusions and presentations, oral and written communication strategies. This engagement of the research participants places the researchers under the control of their social partners. If the mutual trust relations are correctly established, a true, critical, open and constructive dialogue is possible and makes the data collection, data analyses and conclusions of the research stronger. This way, social validation increases the validity of qualitative research (Cho and Trent, 2016).

Finally, participatory research posits research as an open-ended, partly unpredictable, learning process, for all participants including the researchers. It therefore encourages a reflexive and critical analysis of the researchers' positioning, interests and agenda in the research process. From an epistemological point of view, Balcazar (2003) states that the first proposal of PR is an experience that allows participants to "learn how to learn". This is a position also influenced by Freire, which implies understanding participants' role in the process of transformation of their social reality, not as victims or passive spectators, but as central actors in the process of change. During the PR process, participants are involved in deliberative projects that require them to assume leadership in their local communities. This involvement relates to the concept of empowerment in the sense that it develops the necessary capacities to enhance the possibilities for a person to decide and act consistently on all that affects their own life (Soler Masó et al., 2017). In such processes, participation constitutes a methodological principle for achieving the mentioned goal. As the same time, the participation process involves critical and creative reflection. It is considered a right and an opportunity for learning and for raising awareness. From this perspective, participation generates a first level of group empowerment that presupposes the creation of a collective subject capable of reflecting with critical awareness (Mata-Codesal et al., 2018).

Regarding the second constituent element of PR, action, participatory research is from the outset much better positioned as traditional qualitative or quantitative research, as it puts action first. Participatory researchers try and engage the participants who can themselves make the situation 


\section{Strengths, Risks and Limits of Doing Participatory Research in Migration Studies}

evolve, and not only help us understand, describe, analyse, and report it. The outreach of research beyond academia and its higher societal impacts are not by-products of research process but its core motivation. Although the process of social transformation might be very difficult and unsuccessful, the reflection on action and social transformation is present from the beginning of the research project and informs its design. Furthermore, this reflection on intended social transformations is shared with the research participants, making it more probable that the final outreach of the research meets true social expectations.

Finally, we can pose the question of participatory research as being considered more ethical than traditional research. This question has been much debated in some of the workshops on participatory research in migration studies that we have organized in recent years. The answer mostly depends on what is considered "good research" from an ethical perspective. Ethics is extremely challenging in the case of qualitative research regarding delicate, sensitive social topics with vulnerable populations, especially considering the recent requests for open data. In participatory research, ethics is not limited to extracting consent from the participants in oral and written form, signing participation agreement, as well as anonymization of the data for publication. All of these things can be impossible sometimes precisely for ethical reasons. The core of the ethics of participatory research is on building and honouring mutual relations of trust, which rely on the recognition of participants and professional researchers as equal human beings who want to enter into relation to collaborate on a specific topic, with specific methods and a structured process. It also requires conscientization of the structural power relations within and beyond the research process.

\section{Power Issues in Participatory Research}

Following an extensive literature review on the involvement of migrants in health-related participatory research, Vaughn and colleagues concluded that partnering with immigrants have numerous benefits for immigrants and their communities: "it has the potential to positively influence immigrants through the development of practical skills, community awareness, community action and change, and possible health outcomes" (Vaughn et al., 2017, p. 1465). However, the ways in which migrants are involved in PR do not always reach the highest participation levels identified by Sherry Arnstein (1969). Returning to Arnstein's words at the beginning of this article, we cannot emphasize enough that participation is all about power distribution: in order for PR to become really such, researchers must share power. Conflict in the form of tensions among differing schedules of the academic and non-academics participants, different objectives or unlike ways of doing is often mentioned in accounts of participatory research projects. As redistribution attempts are regularly met with conflict, we could even argue that if there is no conflict, then it may not be true participation. Hence, instead of taking conflict as an undesirable outcome of PR, we need to find ways to incorporate it into research in a way that accounts for it and feeds back into the research.

Power constitutes an optimal lens through which to understand specific elements in the application of PR in migration studies. In particular, power asymmetries explain the presence and absence of specific groups and topics in PR, as well as the consideration and level of implementation of PR regarding geographies and disciplines.

PR has been frequently applied when working along/with vulnerable groups. Although some authors have noted the advantages of using PR working with specific vulnerable populations (Aldridge, 2014), there is no practical reason why PR cannot be used for other types of non- 
marginalized (or not totally marginal) groups (Riaño, 2016). This is not exclusively of PR but a general trend in research where groups previously marked as problematic become research topics (Delgado, 1999, p.10), while elites and other powerful groups remain as unmarked categories of research. This tendency can create participation biases that need to be dealt with.

The gendered nature of this SI authorship (all but one being female scholars) is not random. It reflects a propensity of PR to be applied by female academics. This gendered nature of PR was one of the elements often discussed in the different meetings we have set up over the years, since we suspect that this intriguing element was hiding more far-reaching consequences of PR in particular, and the way research and knowledge-production is conceived in general. The feminization of the politics and practices of care in our society was put forward in some of those meetings as an explanation for this gender imbalance, as PR can be conceived as a more caring way of pursuing research. However, this care hypothesis does not explain why, in parts of the world, this gender unbalance is not present. Participatory methods are used in Latin America indistinctly by both male and female scholars, but in the European and Anglo-Saxon world mostly by female academics. A more satisfying explanation would relate to the power hierarchies that structure current Academia. In Latin America, PR has a long and respectable tradition, with key figures like the already mentioned Brazilian Paulo Freire, or Colombian Fals Borda ${ }^{4}$. Given that participatory methods are established, using them is considered as "proper" research. Meanwhile in Europe and the US, and more so in the field migration studies, PR does not account for the level of peer prestige it has in Latin America. We could argue then that only when a methodology becomes established and recognized, established and recognized scholars start using it. That would explain why in European and the Anglo-Saxon Academia, it is mostly women (who are often early career researchers or in precarious job situations) apply PR.

Power hierarchies would also explain the uneven application of PR among traditional disciplines. The so-called "participatory turn" has remained almost unnoticed in disciplines like economics, law or even political science. Within social sciences, these are considered as "powerful" or hard disciplines. Flora Di Donato's article in this special issue provides a good perspective of the limited application of PR in law where even basic collaboration is considered as PR. On the opposite side of the hierarchy, PR is more common in disciplines and subfields like development studies, gender studies, education or social anthropology where a growing number of research projects present some sort of participatory elements.

\section{Acknowledging the Limits of Participatory Research}

Several of the articles in this SI caution about the limits and risks of working with participatory research in the context of a productivity-driven neoliberal academia in a time where outreach beyond academia is becoming a must. Aaron Malone analyses the risks of implementing lite or faux forms of PR in a context where neoliberal academia has been prone to accept watered-down versions of participation where no actual re-distribution of power takes place. Furthermore, Valerie Francisco-Menchavez and Ethel Tungohan, who self-define as women of colour and scholar activists, explore the tensions between the requirements on scholars of that same neoliberal academia and the purposes of participatory research for non-academic partners. In a context of strong pressure to produce research in the form of publications, the timings and tempos of PR are

\footnotetext{
1989).
}

${ }^{4}$ Also, two early world meetings about participatory research were held in the region (in Colombia in 1977 and Nicaragua in 


\section{Strengths, Risks and Limits of Doing Participatory Research in Migration Studies}

difficult to accommodate, and the risks of implementing projects which look like PR, but which do not involve meaningful forms of participation, are very real. Carrying PR in the current academic context requires a careful and continuous consideration of every step taken, so not to let down the core principles of PR that are mostly related to redressing power imbalances, in society and academia in general, and between researchers and companions in PR projects. Thus, PR urges us to explore the politics of knowledge production.

Researchers using PR should avoid conflating the (political and ethical) need to struggle and advocate for social change with a neoliberal entrepreneurial understanding of the self as able to overcome obstacles to social justice which are beyond one's own reach. Placing the burden of social change on marginalized individuals not only blames them for their situation, it also misunderstands the role that neoliberalism, racism, patriarchy, and colonialism play in sustaining systemic structural violence (Walsh 2016, p.407). There are still structural elements which heavily shape social relations. Hence PR must be honest and humble enough not to create high expectations, as research can lead to nowhere reinforcing the sense of marginalization and powerlessness by some groups (as showed by Elsa Oliveira and Jo Vearey in their article in this special issue).

\section{Structure of the Special Issue}

Articles in this special issue are organized in three sections: 1) foundational reflections about participation; 2) risks, limits, and tensions of applying participatory research, and 3) specific applications of participatory research regarding techniques and disciplines. After this introduction which has laid out the state-of-the-art of PR in migration studies, as well as provided some key considerations concerning the constituent elements of PR, the following three articles in the first section expand the discussion on participation as the fundamental element of PR. Martha MonteroSieburth reflects on her extensive experience with PR, including her early engagement with Paulo Freire's work, to provide a fine critique of the often quoted aim of PR, as "giving voice". She convincingly argues that researchers cannot give voice to non-academic participants, as voice is not theirs to give. She advocates instead for researchers working with PR to develop cultural humility. The article by Elsa Oliveira and Jo Vearey, based on a decade of working with marginalized migrants in South Africa using arts-based participatory approaches, shows how PR can lead researchers to engage and confront the current politics of knowledge production, while acknowledging the limits of PR to resolve all power imbalances. Derya Ozkul's article is a cautionary reflection about the potentially oppressive nature of creative methods in PR when selection is just based on researchers' aesthetic needs, and a call to also incorporate participation in the technique selection stage.

The following three articles explicitly deals with the risks, limits and tensions of applying participatory methods in the field of Migration Studies. Aaron Malone's article highlights the tension and challenge of capitalizing on the growing acceptance of participatory research methods while avoiding any descent into a sped-up, watered-down forms of PR driven by the dictates of the neoliberal academia. Through a participatory arts intervention in a Northern Norwegian city, Marit Aure, Anniken Førde and Rebekka Brox Liabø analyse the challenges of co-producing knowledge by accommodating and making sense of multiple knowledge systems by means of constituting what they called "vulnerable spaces of improvisation" in knowledge coproduction. The article by Valerie Francisco-Menchavez and Ethel Tungohan analyses the tension between producing knowledge which is valued by academic standards and useful for community, the different tempos involved, 
and the tactics they have developed to progress in their academic career while still using PR and its protracted timeline.

Finally, the third section of the issue provides good insights into specific techniques, which are frequently used in PR: photovoice (Magdalena Arias Cubas), drifting methods (Tiina Sotkasiira, Sanna Ryynänen, Anni Rannikko and Päivikki Rapo) and participatory theatre (Valerie Stam). The last article by Flora di Donato provides an account of (limited) participatory methods in the discipline of law.

As usual, the current issue of Migration Letters also offers regular articles outside the special issue section.

\section{References}

Aldridge, J. (2014). Working with vulnerable groups in social research: dilemmas by default and design. Qualitative Research, 14(1), 112-130.

Arnstein, S. R. (1969). A ladder of citizen participation. Journal of the American Institute of planners, 35(4), 216-224.

Balcarzar, F. E. (2003). Investigación acción participativa (IAP): Aspectos conceptuales y dificultades de implementación. Fundamentos en Humanidades, 7(8), 59-77

Bradbury, H., and Reason, P. (2006). Conclusion: Broadening the bandwidth of validity: Issues and choice-points for improving the quality of action research. Handbook of action research, pp.343-351.

Caretta, M. A. and Riaño, Y. (2016). Feminist participatory methodologies in geography: creating spaces of inclusion. Qualitative Research, 16(3), 258-266

Cho, J. and Trent, A. (2006). Validity in qualitative research revisited. Qualitative Research, 6(3), 319-340.

Delgado, M. (1999). El Animal Público. Barcelona: Anagrama.

Fox, M., Mediratta, K., Ruglis, J., Stoudt, B., Shah, S., and Fine, M. (2010). Critical youth engagement: Participatory action research and organizing. Handbook of Research on Civic Engagement in Youth, pp.621-649.

Hennink, M.; Hutter, I. and Bailey, A. (2011). Qualitative Research Methods. London: Sage.

Iosifides, T. and Sporton, D. (2009). Biographical methods in migration research. Migration Letters, 6(2), 101-108.

Kontopodis, M. (2012). Neoliberalism, Pedagogy and Human Development: Exploring Time, Mediation and Collectivity in Contemporary Schools. London and New York: Routledge

Lenette, C. (2019). Mental health and critical multicultural practice: An arts-based approach. In Nipperess, S. and Williams, C. (eds.) Critical Multicultural Practice: New Perspectives in Australian Social Work, pp.101-115.

Letiecq, B. and Schmalzbauer, L. (2012). Community-based participatory research with Mexican migrants in a new rural destination: A good fit? Action Research, 10(3), 244-259.

Long, J.; Hylton, K. and Spracklen, K. (2014). Whiteness, blackness and settlement: Leisure and the integration of new migrants. Journal of Ethnic and Migration Studies, 40(11), 1779-1797. https://doi.org/10.1080/ 1369183X.2014.893189.

Mata-Codesal, D.; Pereira, S.; Maiztegui-Oñate, C.; Ulloa, E., Esesumaga, E. and López del Molino. A. (2018). Con la Cámara a Cuestas: Aportaciones de la fotografía en procesos participativos de investigación-intervención. Forum: Qualitative Social Research. 19(1), Art. 14.

Milne, E.J. (2016). Critiquing participatory video: experiences from around the world, Area, 48(4), 401-404.

Mountz, A.; Bonds, A.; Mansfield, B.; Loyd, J.; Hyndman, J., Walton-Roberts, M., Basu, R.; Whitson, R.; Hawkins, R.; Hamilton, T. and Curran, W. (2015). For slow scholarship: A feminist politics of resistance through collective action in the neoliberal university. ACME: An International E-Journal for Critical Geographies, 14(4), 1235-1259.

Pereira, S.; Maiztegi, C. and Mata-Codesal, D. (2016). Transformative Looks. Practicing citizenship through photography, Journal of Social Science Education, 15(4), 14-21.

O'Neill, M. (2008). Transnational refugees: The transformative role of Art? Forum: Qualitative Social Research 9(2), Art. 59.

Riaño, Y. (2016). Minga biographic workshops with highly skilled migrant women: enhancing spaces of inclusion. Qualitative Research, 16(3), 267-279.

Sirkeci, I.; DeTona, C.; Iosifides, T. and Frisina, A. (2019). Reader in Qualitative Methods in Migration Research. London: Transnational Press London 
Soler Masó, P.; Trilla, J.; Jiménez, M. and Ucar Martínez, X. (2017). The construction of a pedagogical model of youth empowerment: spaces, moments and processes. SIPS - Pedagogía Socia. Revista Interuniversitaria, 30, 19-34

Vaughn, L., Jacquez, F. Lindquist-Grantz, R., Parsons, A. and Melink, K. (2017). Immigrants as Research Partners: A Review of Immigrants in Community-Based Participatory Research (CBPR). Immigrant Minority Health, 19, 14571468. Doi: 10.1007/s10903-016-0474-3

Walsh, S. (2016). Critiquing the politics of participatory video and the dangerous romance of liberalism, Area, 48(4), 405-411.

Wang, C. and Burris, M. A. (1997). Photovoice: Concept, methodology, and use for participatory needs assessment. Health Education and Behavior, 24(3), 369-387.

Wiles, R., Crow, G., and Pain, H. (2011). Innovation in qualitative research methods: a narrative review. Qualitative Research, 11(5), 587-604. 